UvA-DARE (Digital Academic Repository)

\title{
Differential expression of CD44 splice variants in the normal human central nervous system
}

Kaaijk, P.; Pals, S.T.; Morsink, F.H.M.; Bosch, D.A.; Troost, D.

DOI

10.1016/S0165-5728(96)00167-1

Publication date

1997

Published in

Journal of neuroimmunology

Link to publication

Citation for published version (APA):

Kaaijk, P., Pals, S. T., Morsink, F. H. M., Bosch, D. A., \& Troost, D. (1997). Differential expression of CD44 splice variants in the normal human central nervous system. Journal of neuroimmunology, 73, 70-76. https://doi.org/10.1016/S0165-5728(96)00167-1

\section{General rights}

It is not permitted to download or to forward/distribute the text or part of it without the consent of the author(s) and/or copyright holder(s), other than for strictly personal, individual use, unless the work is under an open content license (like Creative Commons).

\section{Disclaimer/Complaints regulations}

If you believe that digital publication of certain material infringes any of your rights or (privacy) interests, please let the Library know, stating your reasons. In case of a legitimate complaint, the Library will make the material inaccessible and/or remove it from the website. Please Ask the Library: https://uba.uva.nl/en/contact, or a letter to: Library of the University of Amsterdam, Secretariat, Singel 425, 1012 WP Amsterdam, The Netherlands. You 


\title{
Differential expression of CD44 splice variants in the normal human central nervous system
}

\author{
Patricia Kaaijk ${ }^{\text {a,b }}$, Steven T. Pals ${ }^{\text {a }}$, Folkert Morsink ${ }^{\text {a }}$, D. Andries Bosch ${ }^{\text {b }}$, Dirk Troost ${ }^{\text {a, * }}$ \\ ${ }^{a}$ Department of (Neuro)Pathology, Academic Medical Center, University of Amsterdam, PO Box 22700, 1100 DE Amsterdam, The Netherlands \\ ${ }^{\mathrm{b}}$ Department of Neurosurgery, Academic Medical Center, University of Amsterdam, PO Box 22700, 1100 DE Amsterdam, The Netherlands
}

Received 3 July 1996; revised 28 August 1996; accepted 29 August 1996

\begin{abstract}
Cluster of differentiation 44 (CD44) is a broadly distributed group of glycoproteins that are involved in many functions related to cell-cell and cell-matrix interactions. In the present study, the expression of the standard form of CD44 (CD44s) and of CD44 variants $(\mathrm{CD} 44 \mathrm{v})$ was explored immunohistochemically on frozen sections of various areas of the human CNS. The results demonstrate that CD44s epitopes are expressed predominantly by white matter astrocytes, whereas different CD44 variant molecules are present in neurons, on axonal membranes, on endothelium or on choroid plexus epithelium. Interestingly, neurons and axons differentially expressed CD44 variant epitopes but consistently lack immunoreactivity for CD44s epitopes. Another interesting finding was that some CD44 variant epitopes expressed by neurons were localized in the cytoplasm instead of on the cell membrane. The broad distribution of variant CD44 molecules in the human CNS suggests that CD44 may play an important role in many biological processes in the CNS.
\end{abstract}

Keywords: Central nervous system; CD44 antigen; Adhesion molecule

\section{Introduction}

Cluster of differentiation 44 (CD44) is a broadly distributed family of cell surface glycoproteins involved in cell-cell and cell-matrix adhesive interactions (Jalkanen et al., 1986; Stamenkovic et al., 1989; Miyake et al., 1990; Lesley et al., 1993). Due to alternative RNA splicing which involves at least 10 of the 19 exons, a large number of CD44 isoforms are generated (Screaton et al., 1992; Lesley et al., 1993). In addition, variations in glycosylation contribute to structural and functional diversity of CD44 (Katoh et al., 1995; Lesley et al., 1995). Standard CD44 (CD44s) lacks all 10 variable exons, while variant CD44 isoforms $(\mathrm{CD} 44 \mathrm{v})$ may contain one or more alternatively spliced exons in between standard exons (Lesley et al., 1993). Although, the exact functions of the various CD44 molecules are as yet unclear, members of the CD44 family have been implicated in lymphocyte homing, hematopoiesis and tumor progression, i.e., metastasis and invasion (Jalkanen et al., 1986; Günthert et al., 1991; Koopman et

\footnotetext{
"Corresponding author. Tel.: +31-20-5665635; fax: +31-20-696 0389 .
}

al., 1993; Rudy et al., 1993; Wielenga et al., 1993; Merzak et al., 1994; Manten-Horst et al., 1995).

It has been reported that in the human central nervous system (CNS), CD44s epitopes are expressed predominantly on astrocytes of the white matter (Girgrah et al., 1991; Asher and Bignami, 1992; Moretto et al., 1993). The exact distribution of the CD44 variant isoforms in the CNS, however, is not known. To determine whether CD44 proteins play a role in the normal functioning of the human central nervous system (CNS) assessment of their precise distribution in the CNS is crucial. In the present study, three monoclonal antibodies (mAbs) reacting against CD44s epitopes, and mAbs against epitopes of different CD44 variants: CD44 variant exon 4 (CD44v4), CD44v5, CD44v6 and CD44v10, were used to determine the localization of CD44 isoforms in the human CNS.

\section{Materials and methods}

\subsection{Normal human central nervous tissue}

Normal human nervous system tissue was obtained at autopsy from 5 males and 5 females aged 59 to 87 years, 


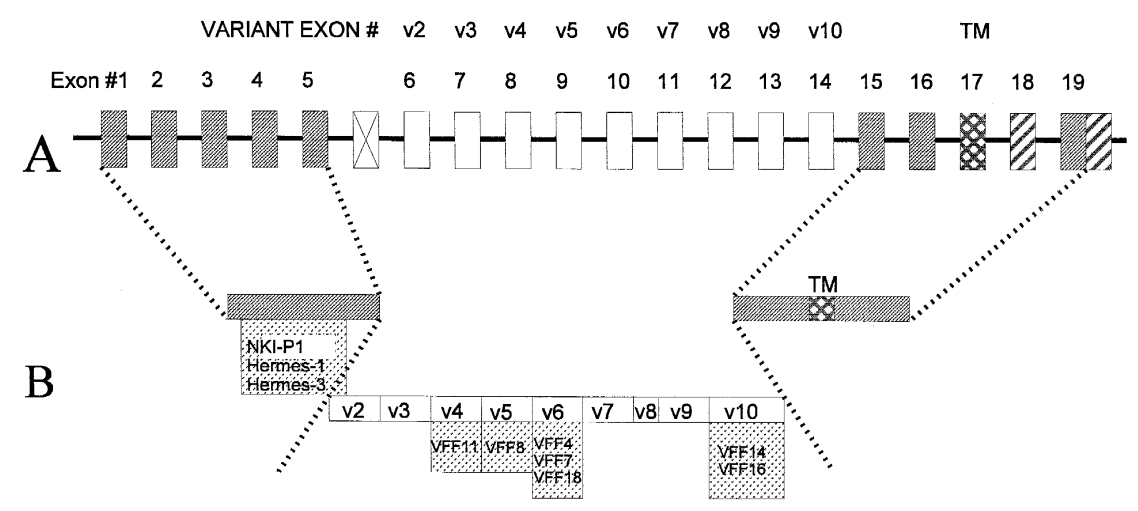

Fig. 1. (A) Schematic representation of the CD44 gene. Open boxes indicate exons that are spliced out of the standard form of CD44. TM, transmembrane region. (B) Schematic representation of the CD44 protein with location of the epitopes which are recognized by the mAbs: NKI-P1, Hermes-1 and Hermes-3, VFF4, VFF7, VFF8, VFF11, VFF14 and VFF16. Dark area, standard form of CD44; v1-v10, domains encoded by the variant exons.

who had died of non-neurological disorders. Within 16 hours after death, samples were taken from the following areas of the central nervous system: precentral gyrus (area 4), area fronto polaris (area 10), primary and secondary visual cortex (area 17/18), area temporo polaris (area 38), gyrus of Heschl (area 42), hippocampus, corpus striatum, thalamus, mesencephalon, medulla oblongata, cerebellum and spinal cord (level C6 and T4). Samples were snapfrozen in liquid nitrogen and stored in a $-80^{\circ} \mathrm{C}$ freezer.

\subsection{Immunohistochemical detection of CD44 variants}

Frozen sections were tested for expression of CD44 splice variants by immunohistochemistry as described previously, using a panel of monoclonal antibodies (mAbs) raised against a bacterially expressed fusion protein encoded by exons v3-10 of the human HPKII-type CD44 (Heider et al., 1993; Koopman et al., 1993). Variant exons v3-10 are corresponding to exons 7-14 of the human genomic CD44 (Heider et al., 1993; Koopman et al., 1993). The structure of CD44 and the location of the epitopes that are recognized by mAbs, NKI-P1, Hermes-1, Hermes-3, VFF11, VFF8, VFF4, VFF7, VFF18, VFF14 and VFF16 are shown in Fig. 1.

\subsection{Reverse transcriptase polymerase chain reaction}

Spinal cord tissue was obtained at autopsy within 16 hours after death from 5 patients who had died of non-neurological disorders. Total cellular RNA was extracted from spinal cord using the lithium chloride/ureum extraction method (Auffray and Rougeon, 1980). Complementary (c) DNA was generated from $2 \mu \mathrm{g}$ RNA using an oligo-dT primer and M-MLV reverse transcriptase from Perkin Elmer Gene Amp RNA-DNA kit (Perkin Elmer Cetus, Norwalk). The cDNA samples were amplified using $5^{\prime}$ and $3^{\prime}$ primers within the constant region of the CD44 gene and flanking the variable region (Koopman et al., 1993). Subsequently, semi-nested PCR was performed on the obtained PCR products with the CD44s $5^{\prime}$ primer and a
CD44 exon v10 3' primer: 5'-TTCGTGTGTGGGTAATGAGAG-3'. A plasmid containing CD44v with exons v3 to v10 was used as a positive control, and destilled water was used as a negative control. PCR products were separated on an ethidium-bromide $1.5 \%$ agarose gel and photographed under UV illumination.

\section{Results}

\subsection{Cerebral cortex and white matter}

The immunohistochemical expression pattern of the CD44 variant epitopes in the human central nervous tissue are summarized in Table 1. All three antibodies against standard CD44 (CD44s) showed the same staining pattern. CD44s was preferentially expressed on fibrillary astrocytes of the white matter and the limiting glial membrane of the cortex. Incidentally, glial cells of the grey matter were CD44s positive. The leptomeninges were strongly CD44s positive. CD44s epitopes were also present on endothelial

Table 1

CD44 splice variants expression on cells and structures of the CNS

\begin{tabular}{|c|c|c|c|c|c|}
\hline Cells /structures & CD44s & CD44v4 & CD44v5 & CD44v6 & CD44v10 \\
\hline $\begin{array}{l}\text { White matter } \\
\text { astrocytes }\end{array}$ & ++ & - & - & - & - \\
\hline $\begin{array}{l}\text { Grey matter } \\
\text { astrocytes }\end{array}$ & + & - & - & - & - \\
\hline Glia limitans & ++ & - & - & - & - \\
\hline Neurons & - & + & + & - & + \\
\hline Axons & - & + & + & - & ++ \\
\hline Endothelium & $+{ }^{a}$ & - & - & - & ++ \\
\hline Choroid plexus & + & ++ & ++ & ++ & ++ \\
\hline Molecular layer & - & + & + & - & - \\
\hline Purkinje cells & - & + & ++ & - & - \\
\hline $\begin{array}{l}\text { Granular layer } \\
\text { (astrocytes) }\end{array}$ & ++ & - & - & - & - \\
\hline Bergmann glia & + & - & - & - & - \\
\hline
\end{tabular}

$++=$ strongly positive; $+=$ positive; $-=$ negative.

${ }^{a}$ The endothelial cells in the grey matter were positive for CD44s epitopes whereas the endothelial cells in the white matter were negative. 
cells of medium-sized arterioles in the grey matter but not in the white matter. Although, neurons were not reactive with the three CD44s mAbs, the mAb against CD44 exon $\mathrm{v} 4(\mathrm{CD} 44 \mathrm{v} 4)$ stained the cytoplasm of intermediate neurons in the white matter. Moreover, CD44v4 and CD44v5 were observed in the cytoplasm of large neurons in the grey matter. No CD44v6 expression was found using three different mAbs against CD44v6. CD44v10 was present in large neurons and axons. Endothelial cells in white and grey matter were also CD44v10 positive.

\subsection{Basal ganglia and brain stem}

CD44s was strongly expressed on glial cells and on the matrix of the basal ganglia. CD44s epitopes were also present on endothelial cells of medium-sized arterioles of the basal ganglia, but not on endothelial cells in the white matter. Neurons or axons were negative for CD44s. In contrast, mAb against CD44v4 stained large neurons and axons of putamen and thalamus. CD44v5 stained large motor neurons in the brain stem. CD44v6 was negative. CD44v10 stained axons and endothelial cells.

\subsection{Hippocampus}

Fig. 2 shows a schematic representation of the CD44 variant expression of the hippocampus. Again, CD44s was expressed predominantly on white matter astrocytes. The choroid plexus epithelium was also CD44s positive, al-
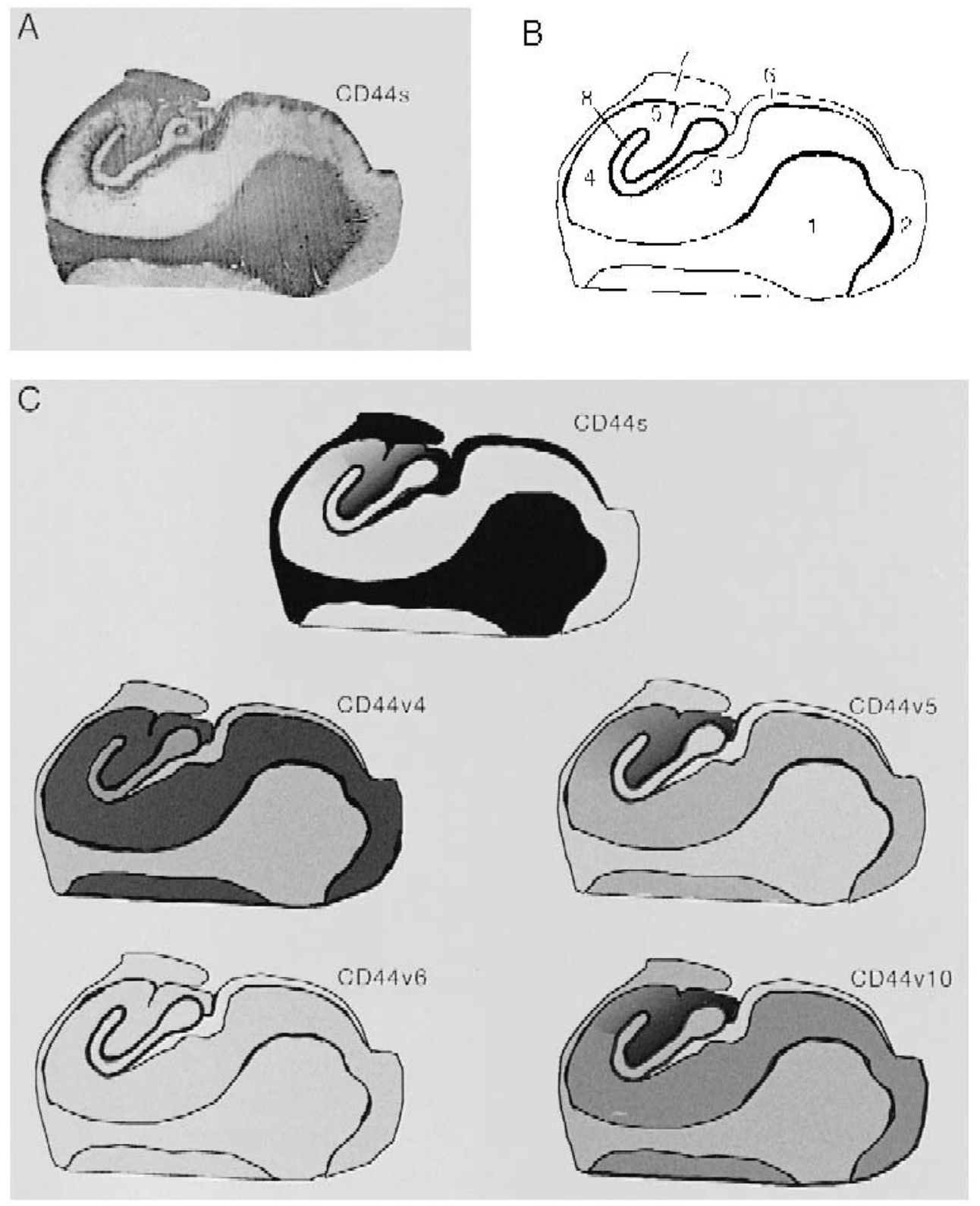

Fig. 2. (A) Photograph of the hippocampus immunostained for CD44s. (B) Schematic representation of the hippocampus: $1=$ white matter; $2=$ entorhinal cortex; 3 = subiculum; $4=$ cornu amonis; $5=$ fascia and gyrus dentatus; $6=$ alveus; $7=$ fimbriae; $8=$ molecular layer. (C) Schematic representations of hippocampi immunostained for, respectively, $C D 44 s, C D 44 v 4, C D 44 v 5, C D 44 v 6$ and $C D 44 v 10$. Darker grey represents stronger staining. 

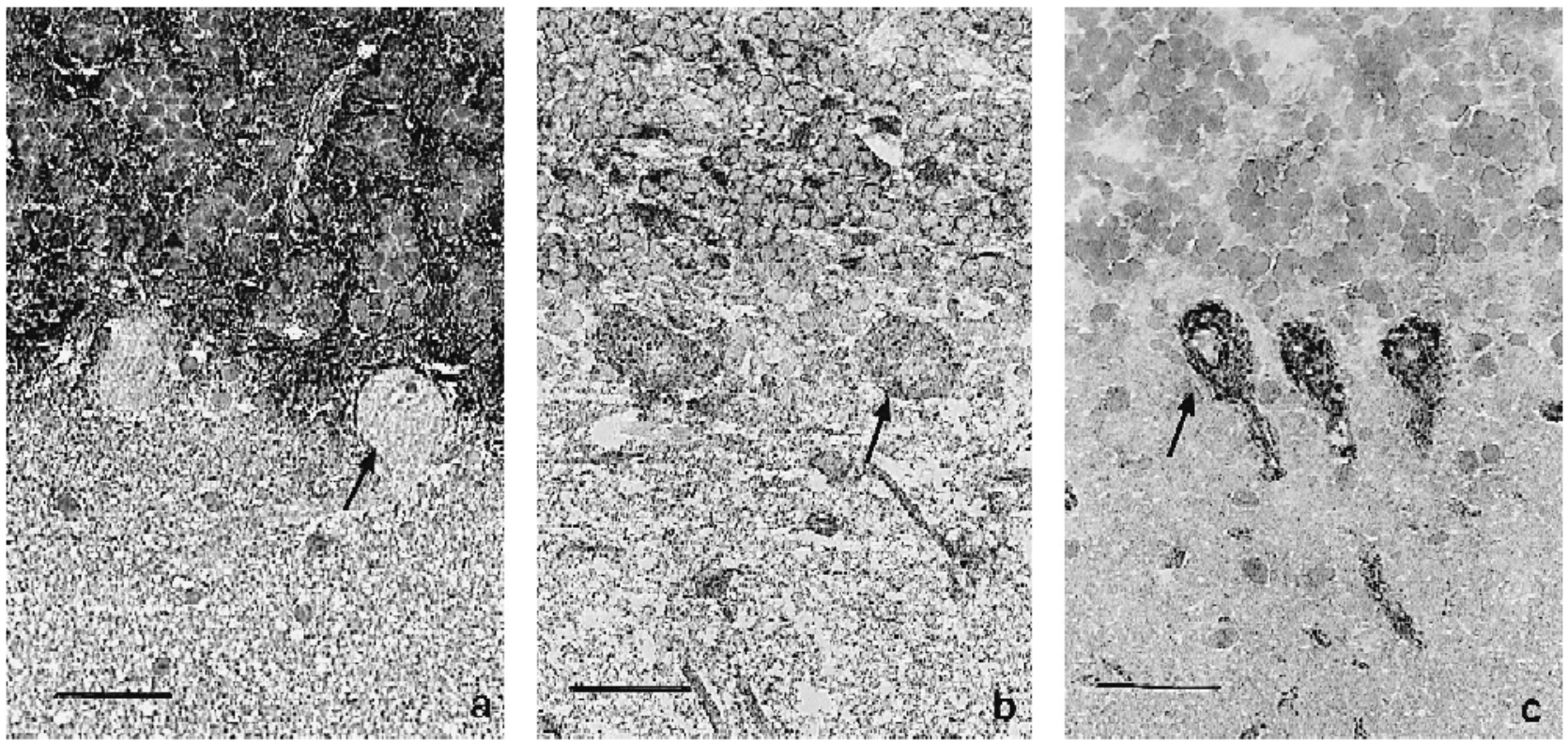

Fig. 3. In the cerebellum, Purkinje cells did not express CD44s epitopes (a), despite these cells and their dendrites showed immunoreactivity for CD44v4 (b) and CD44v5 epitopes (c). Bars $=50 \mu \mathrm{m}$. Arrows indicate Purkinje cells.

though the plexus epithelium was more intensively stained by all mAbs against splice variants. In the hippocampus, no expression of CD44v6 epitopes was observed. Large neurons were positive for $\mathrm{CD} 44 \mathrm{v} 4, \mathrm{CD} 44 \mathrm{v} 5$ and for CD44v10 epitopes. CD44v4 and CD44v10 epitopes were also present on axons. Endothelium was CD44v10 positive.

\subsection{Cerebellum}

The Bergmann glia and the astroglial matrix of the white matter were CD44s positive. Apart from the CD44s positive radiating processes of the Bergmann glia, the molecular layer was negative for CD44s. The entire granular layer was intense positive for CD44s. The cerebellar glomeruli in the granular layer were strongly positive for CD44v4 and v10, and intermediately positive for CD44v5. The glial matrix was negative for all CD44 splice variants. CD44v4 and CD44v5 stained Purkinje cells and their dendrites (Fig. 3), while CD44v5 also stained the neuropil of the molecular layer. CD44v6 was negative on all tissue components in the cerebellum. CD44v10 stained endothelial cells and axons.

\subsection{Spinal cord}

The glial matrix and the lamina gelatinosa were strongly positive for CD44s (Fig. 4). The substantia gelatinosa and axonal membranes were weakly positive for CD44v4. CD44v5 positivity was observed in large motor neurons and on axonal membranes. CD44v6 was negative. CD44v10 showed a strong axonal positivity, the axonal membranes were intensively stained for CD44v10 (Fig. 4).
In the nerve roots besides the axonal membranes, the outer membranes of the myelin sheaths were also CD44v10 positive (Fig. 4). In addition, endothelium was CD44v10 positive.

\subsection{Reverse transcriptase polymerase chain reaction}

To determine whether the discrepant staining patterns obtained with mAbs against CD44s versus CD44v might be due to cross-reaction with other proteins than CD44 in the CNS, we performed rtPCR to detect CD44v at the mRNA level. Using $5^{\prime}$ and $3^{\prime}$ primers within the constant region of the CD44 gene, mRNA of CD44 could be readily amplified from the spinal cord tissue. Subsequently, seminested PCR on these CD44 PCR products was performed using the CD44s $5^{\prime}$ primer and a CD44 exon v10 specific $3^{\prime}$ primer. From this a major PCR product of approximately 1400 basepairs was obtained. The size of this product corresponds to a CD44 isoform containing v10 and most other variant exons.

\section{Discussion}

The standard form of CD44 (CD44s) is widely distributed in lymphoid and non-lymphoid tissues. In contrast, the variant isoforms (CD44v) have a more restricted distribution pattern (Heider et al., 1993; Terpe et al., 1994). In agreement with several other reports, in our study CD44s epitopes are expressed predominantly on the cell surface of astrocytes of the white matter (Girgrah et al., 1991; Asher and Bignami, 1992; Moretto et al., 1993). This CD44s expression might contribute to the migratory capacity of 
white matter astrocytes upon inflammation because the ligand of $\mathrm{CD} 44 \mathrm{~s}$, hyaluronic acid (HA), is the major component of the white matter matrix (Kuppner et al., 1992; Aruffo et al., 1990). In addition, CD44s epitopes are present on endothelial cells of medium-sized arterioles in the grey matter but, not in the white matter. This suggests that the endothelial cells in the grey matter have different adhesive properties compared to endothelium in the white matter, which might be of special interest for Alzheimer's disease where the typical amyloid deposits are localized in grey matter (amyloid angiopathy and plaques), but not in white matter. Epitopes recognized by the mAbs against
CD44v6 appear largely absent in the central nervous system (CNS). CD44v4 and v5 epitopes appear mainly present in the cytoplasm of large neurons, especially in Purkinje cells. The CD44v10 epitope is expressed on endothelial cells, axonal membranes and occasionally on large neurons.

It is remarkable that CD44 splice variants $\mathrm{v} 4$, v5 and $\mathrm{v} 10$, are differentially expressed in neurons and on axonal membranes, while these cells and structures show no immunoreactivity for CD44s epitopes. This phenomenon has been described previously by Salmi and co-workers (Salmi et al., 1993). They found that CD44v6 was expressed on
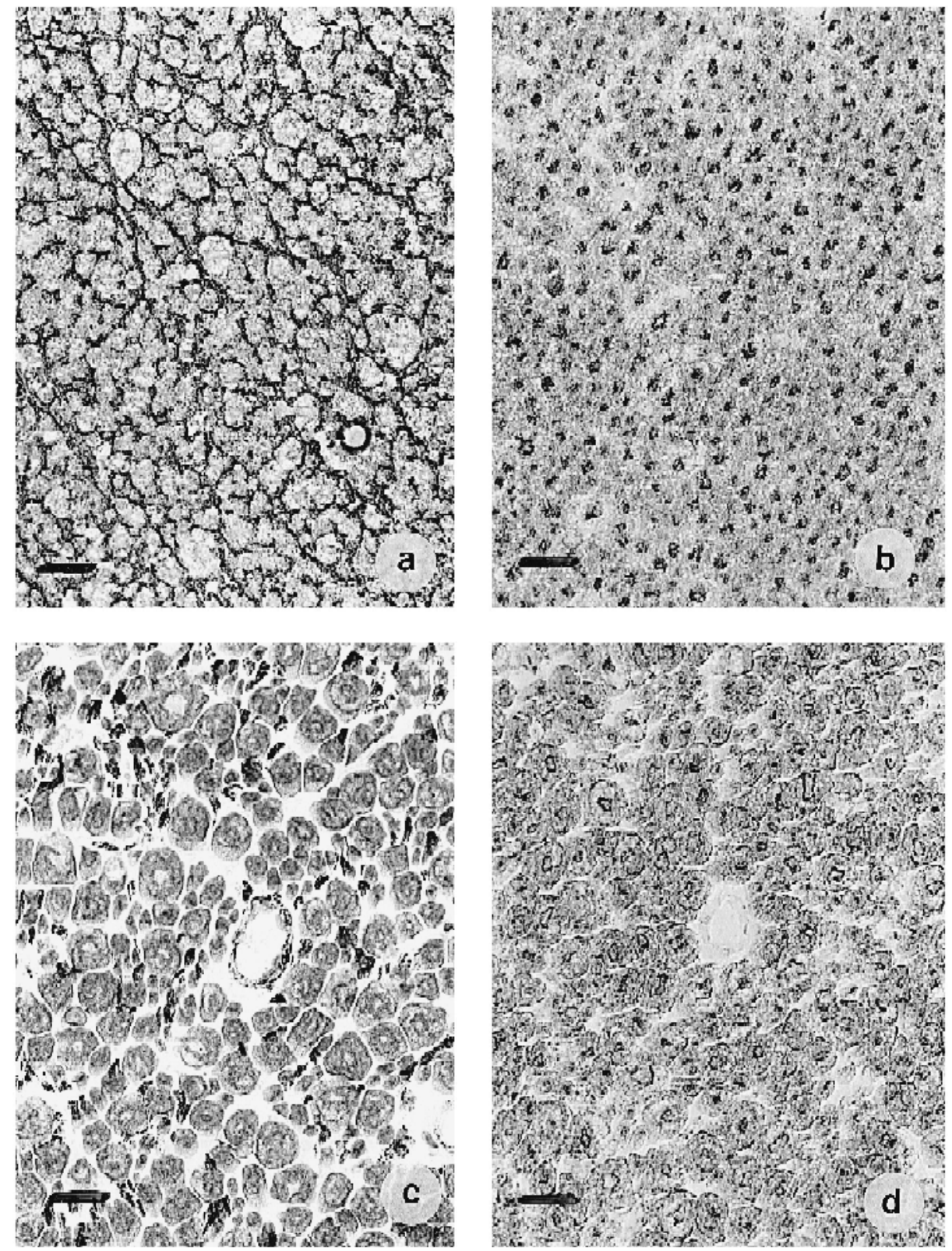

Fig. 4. In the spinal cord, CD44s epitopes (a) were expressed on the astroglial matrix. In contrast, CD44v10 epitopes (b) were expressed on axonal membranes. In the nerve roots, again CD44s epitopes (c) were expressed on astroglial matrix, and CD4410 epitopes (d) were expressed on the axonal membranes as well as on the outer membranes of the myelin sheaths. Bars $=250 \mu \mathrm{m}$ 
high endothelium of blood vessels, while these cells were unreactive with mAbs against CD44s. Theoretically, the discrepant staining patterns obtained with mAbs against CD44s versus CD44v might be due to cross-reaction with other proteins than CD44 in the CNS. However, since we could readily detect mRNA containing CD44v10 in spinal cord tissue by reverse transcriptase polymerase chain reaction (RT-PCR) this is unlikely. Alternatively, novel CNS specific isoforms of CD44 may exist, which lack parts of the 'constant' region of CD44 detected by the three different CD44s antibodies used in this study. Another possibility is that ligand binding of the CD44 variants in the CNS might result in steric or conformational obstruction of the epitopes that are recognized by the anti-CD44s antibodies. Moreover, insertion of CD44 splice variant domains could interfere with binding of the CD44s antibodies. Finally, it has been described that the hyaluronate-binding capacity of CD44 is dependent on the glycosylation of the CD44 molecule (Katoh et al., 1995; Lesley et al., 1995). Differential glycosylation of CD44 molecules, which is likely to occur in the CNS (Sano et al., 1993; Hoffmann et al., 1995), might also interfere with the immunohistochemical detection of CD44s epitopes. Although, it is as yet unclear how it is possible that cells and structures in the CNS are stained with mAbs against CD44 variant epitopes but not with $\mathrm{mAbs}$ against CD44s epitopes, our findings indicate that the assumption, that antibodies against CD44s epitopes detect all CD44 isoforms, might be incorrect.

Another unexpected observation is that the CD44 variants are localized in the cytoplasm of neurons (Fig. 3), whereas these molecules are usually expressed on the cell membrane. A related observation has been described before, CD44v6 has been found to be expressed intracellularly in peripheral blood leukocytes and in epithelial cells (Salmi et al., 1993). The cytoplasmic expression of CD44 molecules suggests intracellular functions of CD44. CD44 variant molecules may be expressed on membranes of organelles or be associated with cytoskeleton proteins.

The functions of the various CD44 splice variants in the CNS are as yet unclear, but the function is probably dependent on the context in which the exon is expressed, i.e., with or without other exons. The broad distribution of the different CD44 molecules in the human CNS suggests that CD44 plays important roles in many biological processes in the CNS.

\section{Acknowledgements}

We thank Drs. G.R. Adolf and E. Patzelt (Bender, Vienna, Austria) for the mAbs against CD44 splice variants and Professor C.G. Figdor (Nijmegen, The Netherlands) for mAb NKI-P1 against CD44s. We thank Dr. F. van den Berg for his help with creating the computer-based images of the hippocampi and Mrs. C. Smit for technical assistance for the molecular biological techniques to detect CD44 at the mRNA level.

\section{References}

Aruffo, A., Stamenkovic, I., Melnick, M., Underhill, C.B. and Seed, B. (1990) CD44 is the principal cell surface receptor for hyaluronate. Cell 61, 1303-1313.

Asher, R. and Bignami, A. (1992) Hyaluronate binding and CD44 expression in human glioblastoma cells and astrocytes. Exp. Cell Res. 203, 80-90.

Auffray, C. and Rougeon, F. (1980) Purification of mouse immunoglobulin heavy-chain messenger RNAs from total myeloma tumor RNA. Eur. J. Biochem. 107, 303-314.

Girgrah, N., Letarte, M., Becker, L.E., Cruz, T.F., Theriault, E. and Moscarello, M.A. (1991) Localization of the CD44 glycoprotein to fibrous astrocytes in normal white matter and to reactive astrocytes in active lesions in multiple sclerosis. J. Neuropath. Exp. Neurol. 50, 779-792.

Günthert, U., Hofmann, M., Rudy, W., Reber, S., Zöller, M., Hausmann, I., Matzku, M., Wenzel, A., Ponta, H. and Herrlich, P. (1991) A new variant of glycoprotein $\mathrm{CD} 44$ confers metastatic potential to rat carcinoma cells. Cell 65, 13-24.

Heider, K.H., Hofmann, M., Horst, E., Van den Berg, F., Ponta, H., Herrlich, P. and Pals, S.T. (1993) A human homologue of rat metastasis-associated variant of CD44 is expressed in colorectal carcinomas and adenomatous polyps. J. Cell Biol. 120, 227-233.

Hoffmann, A., Nimtz, M., Getzlaff, R. and Conradt, H.S. (1995) Braintype $\mathrm{N}$-glycosylation of asialo-transferrin from human cerebrospinal fluid. FEBS Lett. 359, 164-168.

Jalkanen, S.T., Bargatze, R.F., Herron, L.R. and Butcher, E.C. (1986) A lymphoid cell surface glycoprotein involved in endothelial and lymphocyte homing in man. Eur. J. Immunol. 16, 1195-1202.

Katoh, S., Zheng, Z., Oritani, K., Shimazota, T. and Kincade P.W. (1995) Glycosylation of CD44 negatively regulates its recognition of hyaluronan. J. Exp. Med. 192, 419-429.

Koopman, G., Heider, K.-H., Horst, E., Adolf, G.R., Van den Berg, F., Ponta, H., Herrlich, P. and Pals, S.T. (1993) Activated human lymphocytes and aggressive non-Hodgkin's lymphomas express a homologue of the rat metastasis-associated variant of CD44. J. Exp. Med. 177, 897-904.

Kuppner, M.C., Van Meir, E.G., Gauthier, Th., Hamou, H.-F. and De Tribolet, N. (1992) Differential expression of the CD44 molecule in human brain tumours. Int. J. Cancer 50, 572-566.

Lesley, J., Hyman, R. and Kincade, P.W. (1993) CD44 and its interaction with the extracellular matrix. Adv. Immunol. 54, 271-335.

Lesley, J., English, N., Perschl, A., Gregoroff, J. and Hyman, R. (1995) Variant cell lines selected for alterations in the function receptor CD44 show differences in glycosylation. J. Exp. Med. 182, 431-437.

Manten-Horst, E., Danen, E.H.J., Smit, L., Snoek, M., Le Poole, C., Van Muijen, G.N.P., Pals, S.T. and Ruiter, D.J. (1995) Expression of CD44 splice variants in human cutaneous melanoma and melanoma cell lines is related to tumor progression and metastatic potential. Int. J. Cancer 64, 182-188.

Merzak, A., Koocheckpour, S. and Pilkington, G.J. (1994) CD44 mediates human glioma cell adhesion and invasion in vitro. Cancer Res. 54, 3988-3992.

Miyake, K., Underhill, C.B., Lesley, J. and Kincade, P.W. (1990) Hyaluronate can function as a cell adhesion molecule and CD44 participates in hyaluronate recognition. J. Exp. Med. 172, 69-75.

Moretto, G., Xu, R.Y. and Kim, S.U. (1993) CD44 Expression in human astrocytes and oligodendrocytes in culture. J. Neuropath. Exp. Neurol. 52, 419-423.

Rudy, W., Hofmann, M., Schwartz-Albiez, R., Zöller, M., Heider, K.H., Ponta, H. and Herrlich, P. (1993) The two major CD44 proteins expressed on a metastatic rat tumor cell line are derived from different splice variants—each one individually suffices to confer metastatic behavior. Cancer Res. 53, 1262-1268.

Salmi, M., Grön-Virta, K., Sointu, P., Grenman, R., Kalimo, H. and Jalkanen, S. (1993) Regulated expression of exon v6 containing 
isoforms of CD44 in man: downregulation during malignant transformation of tumors of squamocellular origin. J. Cell Biol. 122, 431-442.

Sano, S., Kudo, J and Fujita, S.C. (1993) Different subsets of CNS neurons express different glycosaminoglycan epitopes on large perineuronal proteoglycans. Brain Res. 630, 65-74.

Screaton, G.F., Bell, M.V., Jackson, D., Cornelius, F.B., Gerth, U. and Bell, J. (1992) Genomic structure of DNA encoding the lymphocyte homing receptor CD44 reveals at least 12 alternative spliced exons. Proc. Natl. Acad. Sci. 89, 12,160-12,164.

Stamenkovic, I., Amiot, M., Pesando, J.M. and Seed, B. (1989) A lymphocyte molecule implicated in lymph node homing is a member of the cartilage link protein family. Cell 56, 1057-1062.

Terpe, H.-J., Stark, H., Prehm, P. and Günthert, U. (1994) CD44 variant isoforms are preferentially expressed in basal epithelia of non-malignant human fetal and adult tissues. Histochem. 101, 79-89.

Wielenga, V.J.M., Heider, K.H., Offerhaus, G.J.A., Adolf, G.R., Van den Berg, F., Ponta. H., Herrlich, P. and Pals, S.T. (1993) Expression of CD44 variant proteins in human colorectal cancer is related to tumor progression. Cancer Res. 53, 4754-4756. 